\title{
AN OPTIMIZED MODEL FOR OPEN INNOVATION SUCCESS IN MANUFACTURING SMES
}

\author{
Amir Hakaki $^{1}{ }^{\circledR}$, Mohsen Shafiei Nikabadi $^{1, *}$ And Mahnaz Ali Heidarloo ${ }^{2}$
}

\begin{abstract}
Given the fluctuations in markets and the financial and resource constraints of SMEs, innovation is one of the solutions for improving performance, gaining competitive advantage and increasing survival probability for these companies. The paper aims to determine the best ranking of effective factors in open innovation success in manufacturing SMEs. At the first stage, the most important factors investigated using structural equation modelling based on the opinion of 275 experts. Subsequently, the impact level of each factor on the others calculated by fuzzy DEMATEL among 12 specialists' viewpoints. In the end, optimized ranking of studied factors obtained by Ant Colony Optimization algorithm. As a result, economic factors, suppliers, competitors, partners, firm's strategy, firm's structure, reward system, employees, IT support, organizational learning, universities, research institutions, and ecological issues hold the first to the thirteenth rank with the highest cumulative impact on open innovation success. Developing relations with universities and research institutions for improving innovation process is recommended to manufacturing SMEs. In addition, these companies should coordinate firm's strategy as one of the most important open innovation success factors with partners to gain competitive advantages against competitors.
\end{abstract}

Mathematics Subject Classification. 68T20.

Received May 5, 2021. Accepted October 20, 2021.

\section{INTRODUCTION}

Nowadays innovation is considered as a key factor in businesses' success in market and economic sectors [4], which can result in competitive advantage, and performance improvement [25]. Generally, there are two mainstream paradigms in this context: Closed Innovation (CI) and Open Innovation (OI) $[14,16]$. CI paradigm refers to internal exploration, development and commercialization of a technology in organizations [15,33]. However, in OI paradigm, which was first introduced by Henry Chesbrough in 2003 [5,47], knowledge is transferred easily from inside and outside of the organizations [25,28]. Thus, firms cannot rely on their internal research and they can benefit from purchasing innovations or licenses from other companies if necessary [2]. In fact, OI is a process, in which external ideas are welcomed as well as internal ones [29] and the borders between organizations and environment are penetrable, which facilitates knowledge transfer [33]. One of the main purposes of knowledge

Keywords. Open Innovation, Fuzzy DEMATEL, optimization, Ant Colony, Artificial Intelligence.

1 Department of Industrial Management, Faculty of Economics, Management and Administrative Sciences, Semnan University, Semnan, Iran.

2 Department of Industrial Management, Faculty of Human Sciences, Shahed University, Tehran, Iran.

*Corresponding author: shafiei@semnan.ac.ir 
transfer is to improve the performance of $\mathrm{R} \& \mathrm{D}$ department $[5,8]$. Studies show that applying OI can increase the success rate of products to $50 \%$; also, it can elevate firms' R\&D productivity rate to $60 \%$ [9,22]. Generally, OI must be used not only in high-tech but also in low-tech industries $[16,17]$ in order to pursue technological advances [12].

In OI model, companies must discover new opportunities beyond their borders and their limited resources [43] by cooperation with other organizations including universities, suppliers, partners, customers, rivals, and internal usage of IP or patent permissions $[1,2,40]$. Exploring new opportunities to achieve new knowledge and technology [30], especially in Small and Medium Enterprises (SMEs) helps overcoming innovation obstacles $[31,35,41]$, since they are not able to do independent research on account of their limited resources, size and target market $[32,42]$. However, SMEs have the highest proportion of active firms in developing countries and are of great importance in formation of innovations as the majority of active firms in service and production sectors [3]. Moreover, they play a critical role in growth, development and industrialization of economies around the world $[5,40]$. In Iran, about $30 \%$ of economic productivity is made by SMEs among which $75 \%$ are manufacturing enterprises [44].

Although OI has attracted the attention of scholars over the last decade $[5,6,16,18,22,26,29,33,42,46,49]$, there are few holistic studies in the realm of OI in Manufacturing SMEs (MSMEs) specially by using artificial intelligence. Given the importance of these companies $[36,38,43]$ and the issue that OI is usually considered as an important and critical challenge for managers [44]. Due to closing the gap particularly in developing countries such as Iran and the necessity of OI as a strategic view in MSMEs in many world's economies [5,9], it is expected that identifying the most important effective factors and ranking them with the aim of achieving the highest cumulative impact on OI success is helpful for MSMEs. Thus, the research is composed of three stages based on the final goal:

- The first stage: identifying the most important key success factors in OI in MSMEs.

- The second stage: studying impact level of each identified factor on the others one by one by fuzzy DEMATEL technique to create a graph based on asymmetric travelling salesman problem.

- The third stage: investigating the best ranking of studied factors to maximize the accumulative impact of them on OI success by Ant Colony Optimization algorithm.

Given the complexity of the subject, the contribution to the science of this paper is to create an understanding framework related to OI success key factors. Besides, the use of metaheuristic algorithm in the ranking of OI success factors have not been observed in previous studies so it considers as another aspect of innovation for current research. The consequences of the research could help managers to design appropriate policy for improving innovation and R\&D productivity develop sales strategies.

\section{LiterATURE REVIEW}

\subsection{Open Innovation}

OI paradigm holding the view that the $\mathrm{R} \& \mathrm{D}$ borders should widely open not only for implementing external ideas but also for offering internal ideas to the market [17, 29,43]. Unlike CI paradigm, it is believed that absorbing the external knowledge will result in competitive advantage [47] by involving customers, suppliers, research institutions and their partners in innovation process [23]. Table 1 indicates the differences between CI and OI [19].

OI roots in "Exploration" and "Exploitation" [35], which are involved with searching and integrating external knowledge and new technologies [30] through creating a co-operation network with universities, suppliers, partners and customers for development [17]. Previous studies demonstrate three main processes for OI $[8,16,22,29,42,44,49]$.

- Inside-Out process: companies are interested in knowledge entrance from external resources such as suppliers and customers. 
TABLE 1. The most important features of OI \& CI.

\begin{tabular}{ll}
\hline \hline Open Innovation & Closed Innovation \\
\hline Smart People tap into world & Smart People work for us \\
Using internal and external R\&D & Developing internal R\&D \\
Claim own proportion of value & Discover, develop, market \\
Better business model first & The First, Fastest, Fittest \\
Use internal and external ideas & Create the most and the best ideas \\
Trade IP & Control closed IP \\
\hline
\end{tabular}

- Outside-In process: companies search external organizations with appropriate business models, which use their technologies better.

- Coupled process: companies pursue active co-operations and mutual investment with partners to maximize technological capacities of themselves and other organizations.

\subsection{Background}

In recent years, several studies have conducted on the context of innovation and OI, some of the most important studies are listed in Table 2.

Previous studies of OI reviewed with the aim of identifying initial list of PI Success factors to investigate the most important of them among manufacturing SMEs. Section 3.3 discuss identifying initial list of OI success factors. In addition, based on literature review, although there are a lot of researches which conducted among SMEs $[9,40]$, few studies can be found that have focused on manufacturing SMEs.

In terms of research methodology, given the novelty of OI in many research areas such as SMEs, many studies can be found that try to provide a clear definition of this concept by using qualitative methods such as theory building $[12,16]$, content analysis $[8,9,33,36]$, and etc. Moreover, it can be seen that other researches try to aggregate the results of previous studies using systematic review techniques $[5,46,48]$ or investigate OI's dimensions by using path analysis $[6,40,42]$. However, in terms of using fuzzy DEMATEL and metaheuristic algorithms in OI researches, there are several researches which focused on different dimensions of innovation by fuzzy DEMATEL or DEMATEL. For instance, Feng and Ma [24] conducted a research in the field of service innovation to investigate effective factors by fuzzy DEMATEL. Chen et al. [13] evaluated innovative value propositions for smart product service system using fuzzy DEMATEL method. Besides, Chen and Chen [11] studied innovation support system by combination of DEMATEL, fuzzy ANP, and TOPSIS. In the field of OI, Shafiei Nikabadi and Hakaki [43] presented a dynamic model of effective factors on OI based on a hybrid approach including fuzzy DEMATEL and System Dynamics. Besides, they conducted another research to present causal diagram of OI effective factors by fuzzy DEMATEL [44]. However, Studies show that investigating of OI dimensions using the fuzzy DEMATEL approach or its combination with other methods considered rarely. Overall, reviewing of the OI literature shows that combined approach of fuzzy DEMATEL and metaheuristic algorithms such as Ant Colony in the field manufacturing SMEs has not been used yet.

\subsection{OI success factors}

OI needs great changes and overcoming obstacles in organizations, which can stop the migration from CI to OI $[16,38]$. The study of 107 European companies shows various factors considered as obstacles of implementing successful OI such as high costs of coordination, finding appropriate partner, financial resources and time [21]. However, another research on 485 European industrial companies shows that applying OI had led to higher financial productivity [16]. Outsourcing R\&D activities is among the early steps toward OI, in order to lower costs, risks and using complimentary assets for growth [43]. Nevertheless, studies demonstrate the sole 
TABLE 2. Recent studies on OI.

\begin{tabular}{|c|c|c|c|}
\hline Title & Citation & Methodology & Findings \\
\hline $\begin{array}{l}\text { The Adoption of Open Inno- } \\
\text { vation in Large Firms }\end{array}$ & {$[8]$} & $\begin{array}{l}\text { Content } \\
\text { Analysis }\end{array}$ & $\begin{array}{l}\text { Internal resources, universities, research institutions, } \\
\text { competitors, suppliers and customers are involved with } \\
\text { OI process }\end{array}$ \\
\hline $\begin{array}{l}\text { OI: Research, Practices, and } \\
\text { Policies }\end{array}$ & {$[5]$} & $\begin{array}{l}\text { Systematic } \\
\text { Review }\end{array}$ & $\begin{array}{l}\text { This article describes the state of open innovation at the } \\
\text { intersection of research, practice, and policy }\end{array}$ \\
\hline $\begin{array}{l}\text { The human side of OI: The } \\
\text { role of employee diversity in } \\
\text { firm-level openness }\end{array}$ & {$[6]$} & $\begin{array}{l}\text { Regression } \\
\text { Model }\end{array}$ & $\begin{array}{l}\text { There is no direct association between employees' work } \\
\text { history diversity and firm-level openness }\end{array}$ \\
\hline $\begin{array}{l}\text { The Internet of Things: } \\
\text { Building a knowledge } \\
\text { management system for OI } \\
\text { and knowledge } \\
\text { management capacity }\end{array}$ & {$[42]$} & Path Analysis & $\begin{array}{l}\text { Knowledge management system facilitates the creation of } \\
\text { open and collaborative ecosystems, and the exploitation } \\
\text { of internal and external flows of knowledge }\end{array}$ \\
\hline $\begin{array}{l}\text { The Importance of Connect- } \\
\text { ing OI to Strategy }\end{array}$ & {$[49]$} & $\begin{array}{l}\text { Theorizing } \\
\text { existing } \\
\text { strategy }\end{array}$ & $\begin{array}{l}\text { Connecting OI to strategy focuses on OI process, part- } \\
\text { ners, financial resources, knowledge management }\end{array}$ \\
\hline The Future of OI & {$[16]$} & $\begin{array}{l}\text { Theory } \\
\text { Building }\end{array}$ & $\begin{array}{l}\text { future of OI will be more extensive, more collaborative } \\
\text { and engaged with a wider variety of participants }\end{array}$ \\
\hline $\begin{array}{l}\text { Environment detriments of } \\
\text { OI in Dubai SMEs }\end{array}$ & {$[40]$} & $\begin{array}{l}\text { Partial Least } \\
\text { Squares } \\
\text { Modeling }\end{array}$ & $\begin{array}{l}\text { Government support and market dynamics are more } \\
\text { important factors in OI in SMEs than financial resources } \\
\text { and university-industry cooperation }\end{array}$ \\
\hline $\begin{array}{l}\text { Mapping of the Challenges } \\
\text { for the OI Models Imple- } \\
\text { mentation in Service Sector }\end{array}$ & {$[33]$} & $\begin{array}{l}\text { Analyzing } \\
\text { previous } \\
\text { study by } \\
\text { MAXQDA }\end{array}$ & $\begin{array}{l}\text { Challenges classified in } 3 \text { level: change management, IP } \\
\text { protection, and external relationship management }\end{array}$ \\
\hline $\begin{array}{l}\text { Managing OI in SMEs: A } \\
\text { Good practice example of a } \\
\text { German software firm }\end{array}$ & [9] & $\begin{array}{l}\text { Case study: } \\
\text { Content Anal- } \\
\text { ysis }\end{array}$ & $\begin{array}{l}\text { Strategy, process, organizational structure, networking, } \\
\text { IT-support, and organizational culture are necessary for } \\
\text { OI management }\end{array}$ \\
\hline $\begin{array}{l}\text { Open innovation in SMEs- } \\
\text { An intermediated network } \\
\text { model }\end{array}$ & {$[36]$} & $\begin{array}{l}\text { Case study: } \\
\text { Content Anal- } \\
\text { ysis }\end{array}$ & $\begin{array}{l}\text { The paper seeks to place the concept of OI in SMEs; } \\
\text { results indicate networking as one effective way to facili- } \\
\text { tate OI among SMEs }\end{array}$ \\
\hline $\begin{array}{l}\text { Internal and External Fac- } \\
\text { tors Influencing the Imple- } \\
\text { mentation and Diffusion of } \\
\text { the OI Models }\end{array}$ & {$[48]$} & $\begin{array}{l}\text { Systematic } \\
\text { Review }\end{array}$ & $\begin{array}{l}\text { The paper conducted an overview on existing OI } \\
\text { models (internal and external effective factors in OI } \\
\text { management) }\end{array}$ \\
\hline $\begin{array}{l}\text { Factors Influencing an } \\
\text { Organisations ability to } \\
\text { Manage Innovation }\end{array}$ & {$[46]$} & $\begin{array}{l}\text { Systematic } \\
\text { Review }\end{array}$ & $\begin{array}{l}\text { Factors which effect in OI: leadership style, strategy, } \\
\text { organizational structure, resources, technology, knowl- } \\
\text { edge management, employees, culture, process }\end{array}$ \\
\hline
\end{tabular}

outsourcing of R\&D cannot guarantee implementation of OI and other parts of inside or outside of organization must be involved in this process too.

Previous studies are divided into two categories, in terms of factors influencing on OI success; studies such as Pervan et al. [40], Lee et al. [36], and Stucki [48] have focused on external factors. The others like Bogers et al. [6] and Smith et al. [46] have only concentrated on internal factors. However, some researches like Vanhaverbeke et al. [49], Brunswicker and Ehrenmann [9], and Brunswicker and Chesbrough [8] have used combined factors. Based on previous studies, initial influencing factors in OI success puts into two groups; intra and extra organizational factors, listed in Table 3. 
TABLE 3. Initial effective factors in OI success (Based on previous studies).

\begin{tabular}{llllll}
\hline \hline \multicolumn{5}{c}{ Extra-organizational factors } \\
\hline $\mathrm{E}_{1}$ & Competitors & {$[5,6,8,23,48]$} & $\mathrm{E}_{8}$ & Economic factors & {$[40,48]$} \\
$\mathrm{E}_{2}$ & Partners & {$[5,8,9,16,17,36,48,49]$} & $\mathrm{E}_{9}$ & Political/Legal factors & {$[48]$} \\
$\mathrm{E}_{3}$ & Universities & {$[8,17,36,40]$} & $\mathrm{E}_{10}$ & Ecological issues & {$[48]$} \\
$\mathrm{E}_{4}$ & Research institutions & {$[6,8,23,36]$} & $\mathrm{E}_{11}$ & External search breadth & {$[6]$} \\
$\mathrm{E}_{5}$ & Customers & {$[6,8,17,23,48]$} & $\mathrm{E}_{12}$ & External search depth & {$[6]$} \\
$\mathrm{E}_{6}$ & Suppliers & {$[6,8,17,23]$} & $\mathrm{E}_{13}$ & Technology & {$[48]$} \\
$\mathrm{E}_{7}$ & Government support & {$[40]$} & $\mathrm{E}_{14}$ & Firm size & {$[6,38]$} \\
\hline \multicolumn{2}{c}{ Intra-organizational factors } & \\
\hline $\mathrm{I}_{1}$ & Firm's strategy & {$[5,9,43,46,49]$} & $\mathrm{I}_{10}$ & Outsourcing R\&D & {$[6,8,43]$} \\
$\mathrm{I}_{2}$ & Firm's structure & {$[9,46]$} & $\mathrm{I}_{11}$ & Absorptive capacity & {$[42,47]$} \\
$\mathrm{I}_{3}$ & Leadership style & {$[43,46]$} & $\mathrm{I}_{12}$ & Organisational capabilities & {$[42,47]$} \\
$\mathrm{I}_{4}$ & OI process & {$[9,16,46,49]$} & $\mathrm{I}_{13}$ & Organizational learning & {$[6]$} \\
$\mathrm{I}_{5}$ & Financial resources & {$[40,49]$} & $\mathrm{I}_{14}$ & Organizational culture & {$[9,38,46]$} \\
$\mathrm{I}_{6}$ & Firm's technology & {$[8,12,14,15,36,38,48]$} & $\mathrm{I}_{15}$ & Employees & {$[6,8,9,38,46]$} \\
$\mathrm{I}_{7}$ & Knowledge management & {$[42,45]$} & $\mathrm{I}_{16}$ & Team work & {$[43]$} \\
$\mathrm{I}_{8}$ & IT support & {$[9]$} & $\mathrm{I}_{17}$ & Reward system & {$[43]$} \\
$\mathrm{I}_{9}$ & External relationships & {$[33]$} & & & \\
\hline
\end{tabular}

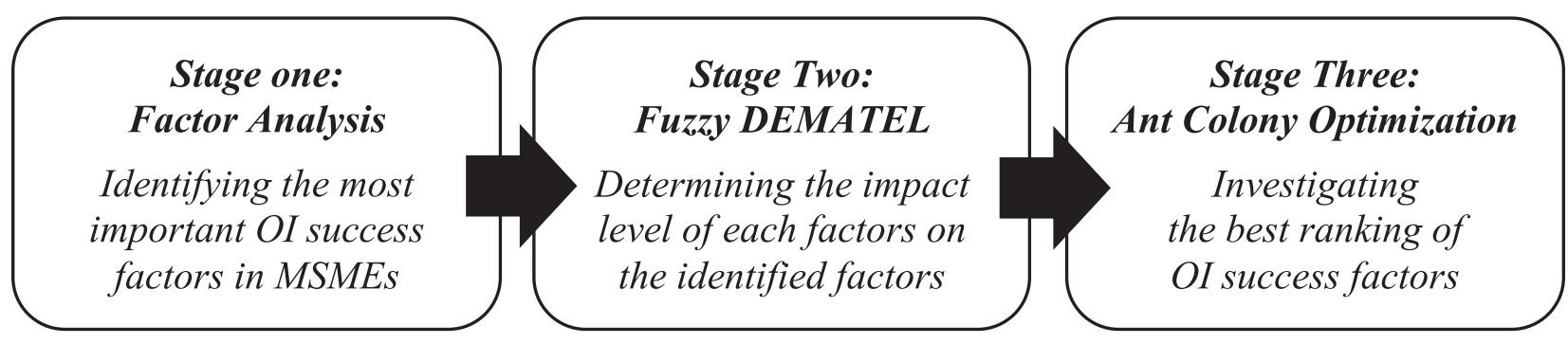

FiguRE 1. Research stages.

\section{ReSEARCH METHOdOLOGY}

In terms of purpose, present study is practical and consists of qualitative variables, placed in the category of descriptive research which done as a survey in three stages (Fig. 1).

As can be seen in Figure 1, in the first stage, the aim is to study the most important OI success factors in MSMEs using Structural Equations Modelling (SEM). Next, in order to investigate the best ranking of studied factors with the highest accumulative impact on OI success in MSMEs, combination of two techniques including fuzzy DEMATEL (Stage Two) and Ant Colony Optimization ACO (Stage Three) have been used.

Although decision support tools such as DEMATEL have been used in various researches with the aim of ranking options or factors, the combination of ranking methods with Artificial Intelligence (AI) has not been considered in none of the previous studies. Therefore, using AI in factors ranking is expected to improve results. In terms of combining research methods, appropriateness of approaches is absolutely essential. One of the outputs of the fuzzy DEMATEL is plotting the cause and effect graph of the studied factors along with determining the effect of each factor on the others. Moreover, the ACO needs to be operated on a graph to make a tour by selecting a point as origin and destination, and traverses the entire nodes of the graph based on routes value. In fact, determining order of nodes by ACO in this study based on the graph obtained from fuzzy 
TABLE 4. Triangular fuzzy number.

\begin{tabular}{lll}
\hline \hline $\begin{array}{l}\text { Linguistic } \\
\text { variable }\end{array}$ & $\begin{array}{l}\text { Definitive } \\
\text { equivalent }\end{array}$ & $\begin{array}{l}\text { Fuzzy } \\
\text { equivalent }\end{array}$ \\
\hline No effect & 0 & $(0.0,0.1,0.3)$ \\
Less effect & 1 & $(0.1,0.3,0.5)$ \\
Mid effect & 2 & $(0.3,0.5,0.7)$ \\
High effect & 3 & $(0.5,0.7,0.9)$ \\
Very high effect & 4 & $(0.7,0.9,1.0)$ \\
\hline
\end{tabular}

DEMATEL is expected to have a good fit in comparison with using other AI algorithms. In the following, each stage of research methodology will be described in details.

\subsection{Stage 1: Factor analysis}

The question of the research in the first stage is: "what is the most important OI success factors in MSMEs?". To answer the question, SEM based on Confirmatory Factor Analysis (CFA) has been applied among initial factors (Tab. 3). Data collected using a questionnaire with 31 questions in two dimensions which its validity were admitted using literature and experts' review. Moreover, questionnaire reliability investigated by Cronbach's Alpha and Composite Reliability. In both methods, the reliability coefficient must be equal to or larger than 0.7. Before SEM tests, Sampling Adequacy examined by Kaiser-Meyer-Olkin (KMO $\geq 0.6$ ) and Bartlett's test $(\mathrm{Sig} \leq 0.05)$. After investigating the significance level $(T$-Value $\geq 1.96)$, indices with factor loading lower than 0.5 are eliminated. To study model fitness AVE $\geq 0.5, R^{2} \geq 0.3, Q^{2} \geq 0.1$ and GOF is calculated based on factors loading [45]. Finally, the remaining factors in the research model are selected as the most important factors in MSMEs.

Statistical population of the research includes a set of managers and experts with at least 3 years work experience in the fields of innovation, R\&D, and NPD management in manufacturing SMEs which their employees are between 50 and 150 persons and active during recent 10 years in Iran. The sample size was set to be 170 individuals chosen purposively, according to least partial squares technique [43].

\subsection{Stage 2: Fuzzy DEMATEL}

With the aim of investigating impact level of each identified factor on the others one by one, fuzzy DEMATEL was applied. Fuzzy sets diminish the ambiguity and uncertainty in goals, preferences and limitations of decision-making problems [10]. The questionnaire was made base on the results of previous stage and DEMTEL methodology. Experts who did know well this methodology checked process of developing questionnaire and confirmed the validity it. The statistical sample in this stage includes 12 experts in the field of innovation management with at least ten years' work experiences in MSMEs (with 50-150 employees and active during recent 10 years) in Iran and related academic degree (at least MA), which are chosen by researchers' judgment and snowball sampling. After taking each expert's opinion by pairwise comparison matrix, their response was changed to triangle FUZZY numbers; $\tilde{x}_{i j}=\left(l_{i j} \cdot m_{i j} \cdot u_{i j}\right)$ according to Table 4 [50].

To calculate definite Total Influence Matrix (TIM), represents the impact level of each factors on the others (as the main input of next stage), 5 phases must be done respectively $[10,50]$ :

Phase one: aggregating experts' opinions to create fuzzy Direct Influence Matrix (DIM) by:

$$
\tilde{z}=\frac{\tilde{x}^{1} \oplus \tilde{x}^{2} \oplus \tilde{x}^{3} \oplus \ldots \oplus x^{p}}{p}
$$

$P$ is the number of experts, and $\tilde{x}^{1}, \tilde{x}^{2}, \ldots, \tilde{x}^{p}$ is pairwise comparison matrix of each expert. 


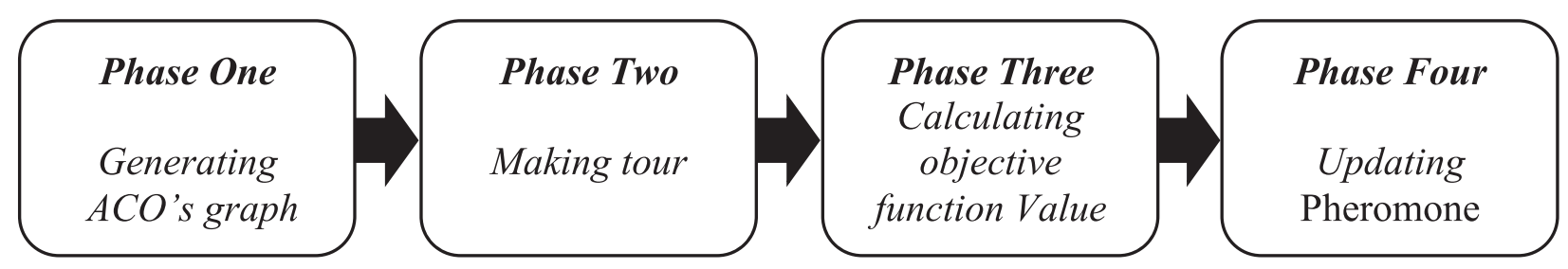

Figure 2. The stages of ACO algorithm design.

Phase two: normalizing fuzzy DIM by dividing each element of DIM to $K$ :

$$
\begin{aligned}
& \tilde{N}=\frac{\mathrm{DIM}}{K} \\
& K=\max _{1 \leq i \leq n}\left(\sum_{j=1}^{n} u_{i j}\right)
\end{aligned}
$$

$\sum_{j=1}^{n} u_{i j}$ calculated by aggregating upper bond of fuzzy numbers for each row of DIM.

Phase three: to construct fuzzy TIM, normalized fuzzy DIM have to divide in three sub-definite matrices first:

$$
N_{l}=\left[\begin{array}{cccc}
0 & l_{12} & \cdots & l_{1 n} \\
l_{21} & 0 & \cdots & l_{2 n} \\
\vdots & \vdots & \ddots & \vdots \\
l_{n 1} & l_{n 2} & \cdots & 0
\end{array}\right] \quad N_{u}=\left[\begin{array}{cccc}
0 & u_{12} & \cdots & u_{1 n} \\
u_{21} & 0 & \cdots & u_{2 n} \\
\vdots & \vdots & \ddots & \vdots \\
u_{n 1} & u_{n 2} & \cdots & 0
\end{array}\right] N_{m}=\left[\begin{array}{cccc}
0 & m_{12} & \cdots & m_{1 n} \\
m_{21} & 0 & \cdots & m_{2 n} \\
\vdots & \vdots & \ddots & \vdots \\
m_{n 1} & m_{n 2} & \cdots & 0
\end{array}\right]
$$

Then, fuzzy TIM computed by summing the direct and indirect influences by:

$$
T_{l}=N_{l} \times\left(I-N_{l}\right)^{-1} \quad T_{m}=N_{m} \times\left(I-N_{m}\right)^{-1} \quad T_{u}=N_{u} \times\left(I-N_{u}\right)^{-1}
$$

$I$ is identity matrix, and each element of TIM calculated according to $\tilde{t}_{i j}=\left(t_{i j}^{l} \cdot t_{i j}^{m} \cdot t_{i j}^{u}\right)$.

Phase four: definite TIM (crisp number) investigates by mean method $\left(\frac{L+M+U}{3}\right)$ for each element of fuzzy TIM.

\subsection{Stage 3: Ant Colony Optimization}

To study the best ranking of investigated factors with the aim of maximizing accumulative impact of them on OI success in MSMEs, Ant Colony Optimization Algorithm (ACO) was applied. Marco Dorigo first introduced this algorithm in 1992 based on the ants' behavior while finding a path between their nests and food source [25]. Proposed algorithm developed in four phases to solve the research problem based on Ant system, according to asymmetric travelling salesman problem (TSP), see Figure 2.

The first phase includes ACO graph formation. The graph nodes number is indicative of the identified factors, extracted in the first stage of the research. Moreover, the effect level of each node on other nodes (the path between each two identified factors) was investigated based on Fuzzy DEMATEL (TIM). Since the effect of factor $A$ on $B$ differs from the effect of factor $B$ on $A$ according to asymmetric TSP, there are two one-way paths between each two nodes. In order to form the distance matrix between each two nodes $(D)$, the entries on TIM matrix main diagonal were set as zero. Then each entry is calculated as $1 / \mathrm{TIM}_{i j}$. Thus, the higher impact level between two nodes results in shorter distance between them.

The second phase is making a tour for each ant. In each repetition each ant chooses a point in the graph accidentally and the possibility of the movement of the ant $K$ from the point $I$ to one of the adjacent points 
TABLE 5. Pre-requisites for entry into the set of SEM's tests.

\begin{tabular}{lllll}
\hline \hline Questionnaire & $\begin{array}{l}\text { Cronbach's } \\
\text { alpha }\end{array}$ & $\begin{array}{l}\text { Composite } \\
\text { reliability }\end{array}$ & $\begin{array}{l}\text { KMO } \\
\text { KMO }\end{array}$ & $\begin{array}{l}\text { Bartlett's } \\
\text { test }\end{array}$ \\
\hline Intra-organizational factors & 0.77 & 0.813390 & 0.620 & Sig $=0.000$ \\
Extra-organizational factors & 0.71 & 0.777696 & 0.615 & $\mathrm{Sig}=0.000$ \\
\hline
\end{tabular}

like $j\left(P_{i j}^{k}\right)$ is defined through equation $(3.6)[27,34,37,39]$.

$$
P_{i j}^{k}= \begin{cases}\frac{\tau_{i j}^{\alpha} \eta_{i j}^{\beta}}{\sum_{m \in N_{i}^{k}} \tau_{i m}^{\alpha} \eta_{i m}^{\beta}} ; & \forall j \in N_{i}^{k} \\ 0 ; & \text { else. }\end{cases}
$$

$N_{i}^{k}$ is a set of nodes not visited by the ant $K$ in the point $i$. The possibility for the paths ending to the visited nodes is zero. $\tau_{i j}$, is the pheromone on the path from $i$ to $j$ and $\eta_{i j}$ is the heuristic measure of the path which equals to $1 / d_{i j}$. $\alpha$ and $\beta$ demonstrate the weight coefficient of the pheromone and heuristic information importance. In the current study, these measures were chosen 1 and 3 respectively. Finally, one tour is made for each ant in each repetition in phase 2 .

The third phase includes calculation of the value of tours made by each ant. The objective function in this algorithm aims to find the shortest path, like TSP. Thus in each repetition, the path with the lowest value is considered the best tour and in total, the best result is referred to the lowest value of objective function in all repetitions.

Through the last phase in each repetition of the algorithm, the pheromones of each ant's path are updated by equation $(3.7)[20,37,39]$.

$$
\tau_{i j}(t+1)=(1-\rho)\left[\tau_{i j}(t)+\frac{1}{\operatorname{ant}(k) \cdot \operatorname{cost}}\right] .
$$

$\tau_{i j}(t)$ shows the level of pheromone on the path. The added pheromone measure is the product of 1 divided by the objective function value for each ant $(\operatorname{ant}(k) \cdot \operatorname{cost})$. Besides, $\rho$ is the evaporation coefficient of pheromones [7], which has been set as 0.9 [27].

The number of ants is 25 and the algorithm will be stopped after 3000 repetitions. After running the ACO algorithm for 40 times, the lowest measure (the shortest distance in TSP and the highest accumulative effects of studied factors on OI success) chosen as the optimized results. The related tour shows the best ranking of the most important factors in OI success in MSMEs.

\section{Results AND Discussion}

\subsection{Stage 1: Factor analysis}

Based on the research goal in the first stage, 275 questionnaires out of 300 were considered appropriate for statistical analyses applying SPSS and SmartPLS. Prerequisites of SEM tests investigated in accordance with Table 5 .

As can be seen in Table 5, all prerequisites of SEM tests were confirmed. Next, $\mathrm{I}_{5}, \mathrm{I}_{10}, \mathrm{I}_{18}, \mathrm{E}_{5}$, and $\mathrm{E}_{6}$ eliminated from the model since their $t$-value were less than 1.96. After reanalyzing $t$-value of remain factors, the factor loadings were studied with the appropriate level of 0.5 ; thus, $\mathrm{I}_{6}, \mathrm{I}_{7}, \mathrm{I}_{9}, \mathrm{I}_{11}, \mathrm{I}_{12}, \mathrm{I}_{14}, \mathrm{I}_{16}, \mathrm{E}_{9}, \mathrm{E}_{11}, \mathrm{E}_{12}$, and $\mathrm{E}_{13}$ were removed. To verify AVE, intra-organizational factors did not reach the limit even after deleting $\mathrm{I}_{4}$, so $\mathrm{I}_{3}$ removed from the model as the lowest factor loading among internal factors. Finally, all model indices were approved (Tab. 6). 
TABLE 6. The most important effective factors in OI success.

\begin{tabular}{|c|c|c|c|c|c|c|c|c|}
\hline Structure & Code & Indices & $t$-value & $\begin{array}{l}\text { Factor } \\
\text { loading }\end{array}$ & AVE & $R^{2}$ & $Q^{2}$ & GOF \\
\hline \multirow{7}{*}{$\begin{array}{l}\text { Internal } \\
\text { factors }\end{array}$} & $\mathrm{I}_{1}$ & Firm's strategy & 6.180 & 0.570 & 0.511 & 0.651 & 0.216 & \multirow{13}{*}{0.574} \\
\hline & $\mathrm{I}_{2}$ & Firm's structure & 10.011 & 0.678 & & & & \\
\hline & $\mathrm{I}_{8}$ & IT support & 7.134 & 0.643 & & & & \\
\hline & $\mathrm{I}_{13}$ & Organizational learning & 11.069 & 0.741 & & & & \\
\hline & $\mathrm{I}_{15}$ & Employees & 5.321 & 0.575 & & & & \\
\hline & $\mathrm{I}_{17}$ & Reward system & 6.341 & 0.523 & & & & \\
\hline & $\mathrm{E}_{1}$ & Competitors & 6.020 & 0.543 & \multirow[t]{7}{*}{0.504} & \multirow[t]{7}{*}{0.648} & \multirow[t]{7}{*}{0.222} & \\
\hline \multirow{6}{*}{$\begin{array}{l}\text { External } \\
\text { factors }\end{array}$} & $\mathrm{E}_{2}$ & Partners & 15.419 & 0.764 & & & & \\
\hline & $\mathrm{E}_{3}$ & Universities & 6.708 & 0.673 & & & & \\
\hline & $\mathrm{E}_{4}$ & Research institutions & 6.577 & 0.669 & & & & \\
\hline & $\mathrm{E}_{6}$ & Suppliers & 5.035 & 0.547 & & & & \\
\hline & $\mathrm{E}_{8}$ & Economic factors & 6.558 & 0.549 & & & & \\
\hline & $\mathrm{E}_{10}$ & Ecological issues & 8.449 & 0.671 & & & & \\
\hline
\end{tabular}

Based on the results in Table $6, \mathrm{I}_{1}, \mathrm{I}_{2}, \mathrm{I}_{8}, \mathrm{I}_{13}, \mathrm{I}_{15}, \mathrm{I}_{17}, \mathrm{E}_{2}, \mathrm{E}_{3}, \mathrm{E}_{4}, \mathrm{E}_{5}, \mathrm{E}_{8}$, and $\mathrm{E}_{10}$ were recognized as the most important OI success factors in MSMEs. It is worth mentioning that GOF is calculated 0.574 , which indicates strong fitness of the research model.

Chesbrough [16] and Vanhaverbeke et al. [48] have also mentioned competitors as an OI success factor. Although Bogers et al. [6], Faems et al. [23], Stucki [48], and Chesbrough and Crowther [17], have introduced customers as an effective factor, current study does not support it. According to the experts, the results are not above expectations since there are no appropriate grounds for customer relationship and following customers' taste and wants in developing countries like Iran. Besides, Pervan et al. [40] introduced government support as an OI success factor. Experts believe that government's ignorance, inappropriate investments in co-operations with R\&D of MSMEs, and lack of appropriate facilities with low interest for MSMEs are the reasons of this difference.

In terms of internal factors, firm's strategy, organizational structure, IT support, organizational learning, employees and reward system are identified as the most important intra-organizational OI factors in MSMEs. Brunswicker and Ehrenmann [9], Mortara and Minshall [38] and Smith et al. [46] have identified organizational culture as an OI success factor. However, the results of this research do not support this finding. Volatile economic situation of production industries in Iran can lead to this difference because this condition challenges the planning and creating an appropriate organizational culture for fundamental innovative research. Besides, Lack of appropriate performance guidelines and lack of knowledge about these concepts among companies' owners can lead to these results as well.

\subsection{Stage 2: Fuzzy DEMATEL}

In order to calculate TIM, the data collected by pairwise comparison matrix filled by 12 experts in the field of OI in MSMEs. Matrices converted to fuzzy triangular numbers and aggregated by fuzzy means to create Fuzzy DIM (Tab. 7).

After computing $\boldsymbol{K}=\mathbf{9 . 1 8}$, fuzzy DIM multiplied by reverse of $K$ to normalize it. Subsequently, based on research methodology, fuzzy TIM calculated and definite TIM obtained based on it according to Table 8 .

Definite TIM (Tab. 7) indicates the level of impact for each factor on the others and it is used as the main input of ACO algorithm (stage 3). Moreover, one of fuzzy DEMATEL outputs which can be compared with results of ACO, the sum of each row should be calculated and ranked from the highest to lowest (H to $\mathrm{L}$ ) in accordance with Table 9. It indicates the effect of each factor on the whole system independently. 

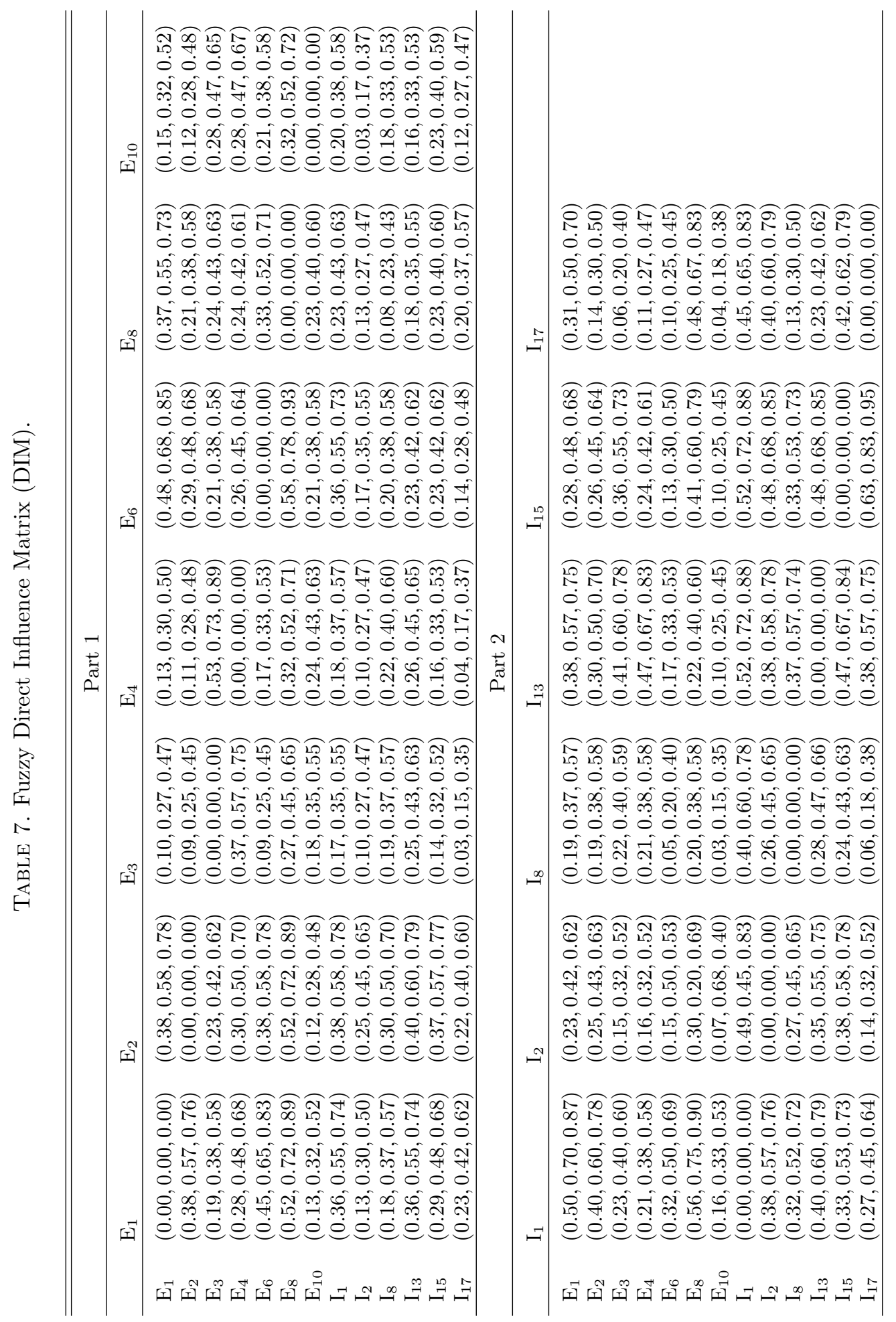
TABLE 8. Total Influence Matrix (TIM).

\begin{tabular}{llllllllllllll}
\hline \hline & $\mathrm{E}_{1}$ & $\mathrm{E}_{2}$ & $\mathrm{E}_{3}$ & $\mathrm{E}_{4}$ & $\mathrm{E}_{6}$ & $\mathrm{E}_{8}$ & $\mathrm{E}_{10}$ & $\mathrm{I}_{1}$ & $\mathrm{I}_{2}$ & $\mathrm{I}_{8}$ & $\mathrm{I}_{13}$ & $\mathrm{I}_{15}$ & $\mathrm{I}_{17}$ \\
\hline $\mathrm{E}_{1}$ & 0.147 & 0.213 & 0.143 & 0.153 & 0.210 & 0.187 & 0.150 & 0.227 & 0.183 & 0.157 & 0.213 & 0.207 & 0.183 \\
$\mathrm{E}_{2}$ & 0.187 & 0.140 & 0.133 & 0.143 & 0.173 & 0.153 & 0.137 & 0.203 & 0.170 & 0.147 & 0.193 & 0.190 & 0.153 \\
$\mathrm{E}_{3}$ & 0.180 & 0.197 & 0.110 & 0.193 & 0.173 & 0.173 & 0.160 & 0.193 & 0.167 & 0.150 & 0.210 & 0.207 & 0.147 \\
$\mathrm{E}_{4}$ & 0.190 & 0.200 & 0.167 & 0.120 & 0.183 & 0.173 & 0.160 & 0.187 & 0.163 & 0.150 & 0.217 & 0.197 & 0.153 \\
$\mathrm{E}_{6}$ & 0.193 & 0.190 & 0.130 & 0.147 & 0.123 & 0.173 & 0.140 & 0.193 & 0.157 & 0.127 & 0.177 & 0.170 & 0.143 \\
$\mathrm{E}_{8}$ & 0.243 & 0.257 & 0.180 & 0.197 & 0.240 & 0.157 & 0.190 & 0.257 & 0.213 & 0.180 & 0.230 & 0.250 & 0.220 \\
$\mathrm{E}_{10}$ & 0.140 & 0.143 & 0.123 & 0.143 & 0.140 & 0.143 & 0.090 & 0.153 & 0.123 & 0.110 & 0.143 & 0.143 & 0.117 \\
$\mathrm{I}_{1}$ & 0.217 & 0.230 & 0.163 & 0.173 & 0.213 & 0.193 & 0.167 & 0.180 & 0.217 & 0.187 & 0.250 & 0.250 & 0.213 \\
$\mathrm{I}_{2}$ & 0.157 & 0.187 & 0.133 & 0.140 & 0.163 & 0.143 & 0.127 & 0.197 & 0.123 & 0.157 & 0.200 & 0.210 & 0.180 \\
$\mathrm{I}_{8}$ & 0.170 & 0.193 & 0.147 & 0.153 & 0.167 & 0.147 & 0.147 & 0.197 & 0.173 & 0.110 & 0.203 & 0.203 & 0.150 \\
$\mathrm{I}_{13}$ & 0.207 & 0.223 & 0.167 & 0.177 & 0.193 & 0.177 & 0.160 & 0.227 & 0.203 & 0.170 & 0.167 & 0.230 & 0.190 \\
$\mathrm{I}_{15}$ & 0.197 & 0.213 & 0.150 & 0.163 & 0.190 & 0.173 & 0.160 & 0.217 & 0.197 & 0.170 & 0.227 & 0.160 & 0.203 \\
$\mathrm{I}_{17}$ & 0.170 & 0.170 & 0.117 & 0.127 & 0.153 & 0.150 & 0.127 & 0.183 & 0.150 & 0.127 & 0.187 & 0.213 & 0.113 \\
\hline
\end{tabular}

TABLE 9. Ranking of studied factors based on fuzzy DEMATEL output.

\begin{tabular}{lll}
\hline \hline Rank & Based on $(R)$ & H to L \\
\hline 1 & Economic factors & 2.814 \\
2 & Strategy of organization & 2.653 \\
3 & Organisational learning & 2.491 \\
4 & Employees & 2.420 \\
5 & Competitors & 2.373 \\
6 & Universities & 2.260 \\
7 & Research institutions & 2.260 \\
8 & IT support & 2.160 \\
9 & Partners & 2.119 \\
10 & Organisational structure & 2.117 \\
11 & Suppliers & 2.063 \\
12 & Reward system & 1.198 \\
13 & Environmental issues & 1.711 \\
\hline
\end{tabular}

TABLE 10. Node number of each studied factor.

\begin{tabular}{llllllllllllll}
\hline \hline Node Number & 1 & 2 & 3 & 4 & 5 & 6 & 7 & 8 & 9 & 10 & 11 & 12 & 13 \\
\hline Factors & $\mathrm{E}_{1}$ & $\mathrm{E}_{2}$ & $\mathrm{E}_{3}$ & $\mathrm{E}_{4}$ & $\mathrm{E}_{6}$ & $\mathrm{E}_{8}$ & $\mathrm{E}_{10}$ & $\mathrm{I}_{1}$ & $\mathrm{I}_{2}$ & $\mathrm{I}_{8}$ & $\mathrm{I}_{13}$ & $\mathrm{I}_{15}$ & $\mathrm{I}_{17}$ \\
\hline
\end{tabular}

\subsection{Stage 3: Ant Colony Optimization}

Towards forming ACO graph based on asymmetric TSP, the entries on TIM's main diagonal were set as 0 and other entries were reversed. To better understanding, a node number was allocated to each studied factor as can be seen in Table 10.

The ACO algorithm was run for 40 times in Matlab software after initial settings. The results are shown in Table 11.

According to Table 9, the variable titled "BestCost", shows the objective function value. The results are indicative of the fact that the 16th run has had the lowest measure (69.048) in TSP, which its reverse shows 
TABLE 11. The results of running ACO for 40 times.

\begin{tabular}{llllllll}
\hline \hline $\begin{array}{l}\text { Run } \\
\text { ACO }\end{array}$ & BestCost & $\begin{array}{l}\text { Run } \\
\text { ACO }\end{array}$ & BestCost & Run ACO & BestCost & $\begin{array}{l}\text { Run } \\
\text { ACO }\end{array}$ & BestCost \\
\hline 1 & 69.210 & 11 & 69.352 & 21 & 69.210 & 31 & 69.317 \\
2 & 69.232 & 12 & 69.352 & 22 & 69.232 & 32 & 69.145 \\
3 & 69.223 & 13 & 69.072 & 23 & 69.232 & 33 & 69.223 \\
4 & 69.165 & 14 & 69.210 & 24 & 69.223 & 34 & 69.239 \\
5 & 69.262 & 15 & 69.145 & 25 & 69.165 & 35 & 69.261 \\
6 & 69.239 & $\mathbf{1 6}$ & $\mathbf{6 9 . 0 4 8}$ & 26 & 69.239 & 36 & 69.210 \\
7 & 69.142 & 17 & 69.232 & 27 & 69.142 & 37 & 69.145 \\
8 & 69.351 & 18 & 69.317 & 28 & 69.351 & 38 & 69.232 \\
9 & 69.262 & 19 & 69.145 & 29 & 69.352 & 39 & 69.223 \\
10 & 69.145 & 20 & 69.223 & 30 & 69.352 & 40 & 69.145 \\
\hline
\end{tabular}

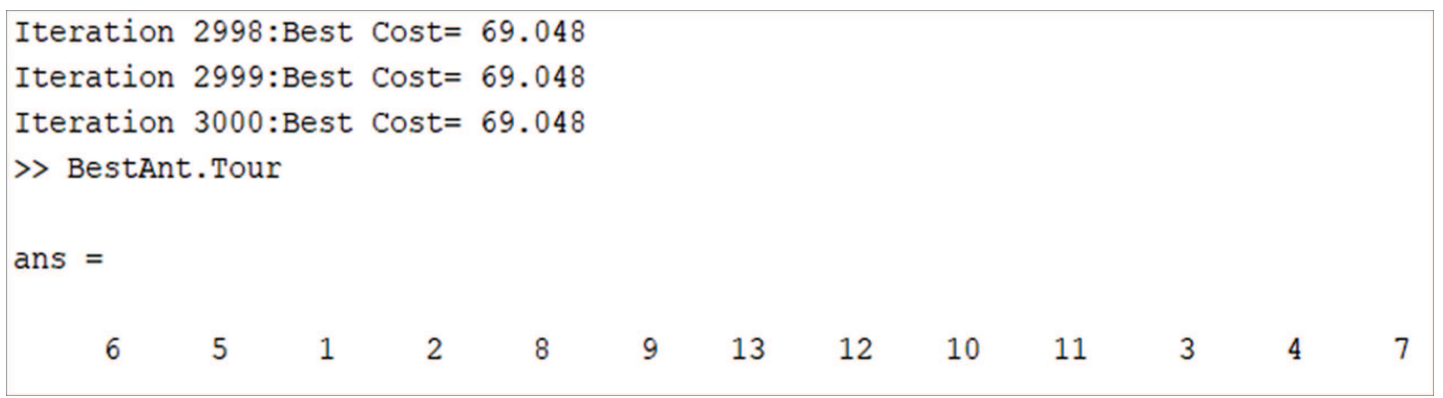

FiguRE 3. The best ranking of the most important effective factors in OI success.

the highest level of cumulative effect on OI success. Figure 3 shows the tour of the 16 th run as the best ranking for the considered factors.

According to Figure 3, the obtained numbers demonstrate nodes number in ACO graph, which formed a tour and was sorted from left to right based on their importance (in descending order). Understandably, ranking and node number of each factor shown in Figure 4 named OI success cycle (Best ranking of OI success factors).

According to Figure 4, the best ranking of the most important factors which has the highest accumulative impact on OI success in MSMEs is as follow: (1) Economic Factors. (2) Suppliers. (3) Competitors. (4) Partners. (5) Firm's Strategy. (6) Firm's Structure. (7) Reward System. (8) Employees. (9) IT Support. (10) Organizational Learning. (11) Universities. (12) Research Institutions. (13) Ecological issues.

To compare the ranking based on Fuzzy DEMATEL with combination of ACO and Fuzzy DEMATEL some points are significant and indicate ACO could improve ranking of studied factors. Although in both methods economic issues are the most important and the most influential factor in OI success, ranking of other factors shows that fuzzy DEMATEL has no operational and practical approach unlike ACO. For example, suppliers, competitors, and partners are ranked 11th, 5th, and 9th respectively using fuzzy DEMATEL. However, they improved to 2nd, 3th, and 4th place respectively using ACO algorithm. According to the experts, ACO improved ranking of studied factors because these external factors should be examined at first to create a clear perspective for organizations to develop their overall plan in terms of strategy, structure, and etc.

Aligned with experts, ACO ranked firm's strategy, firm's structure, reward system, and employees in 5th, 6th, 7th, and 8th place respectively after external effective factors unlike fuzzy DEMATEL. Besides, IT supports ranked 9th using ACO. Experts confirmed the result because after planning of mentioned factors needs to focus 


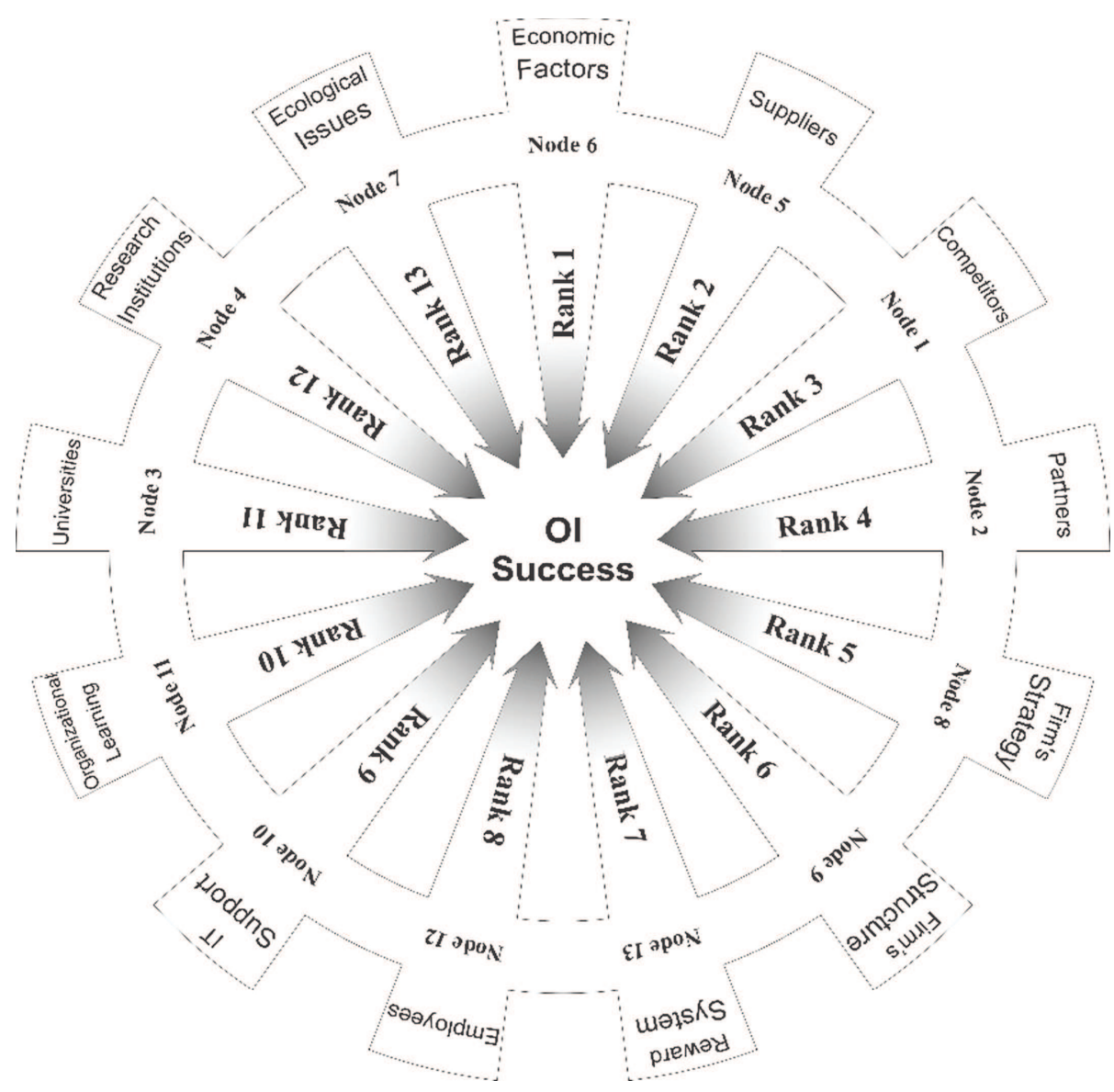

Figure 4. Open innovation success cycle.

on IT supports. Putting organizational learning, universities, research institutions beside each other in ACO ranking can help organizations to implement their innovational strategies successfully through universities and research institutions and improve their learning system. But in fuzzy DEMATEL output these factors was far apart from each other. Finally, ecological issues ranked 13th in both approaches which shows it has no importance for Iranian MSMEs unfortunately.

Overall, ranking of fuzzy DEMATEL has no operational and practical approach unlike ACO. The output of fuzzy DEMATEL ranked factors based on their effect on OI success independently, but combination of ACO and fuzzy DEMATEL ranked factors based on integrated approach and dependence of them with each other to create the maximum accumulative impact on OI success.

The results are indicative of the fact that economic factors are the most important and the most influential factor in OI success. Economic condition has a great importance for SMEs because of their financial resources' limitation. In Iran, frequent and sudden changes of economic factors have imposed great costs to MSMEs in recent years; exchange rate turbulence and its ascending growth, increased bank interest rate and difficulties in production loans repayment, inflation rate increase, decreased purchasing power and economic recession in some markets for some products are among these changes. These has led to a syndrome which makes enterprises focus on economic factors; therefor other factors such as customers have found less priority and even not considered as an influential factor, such as results of this research. Besides, the lowest level of importance belongs to ecological 
issues as the thirteenth factor with the lowest interaction with the others. Experts are of the belief that this stems from production and industrial enterprises concerns about economic factors and governmental ignorance about creating awareness or planning about environmental issues.

More precision at obtained priorities demonstrates that enterprises must pay attention to suppliers, competitors' condition and partners followed by their economic situation. Therefore, they can formulate appropriate strategy for organization and improve their structure based on that. Inappropriate strategy challenges the organization and likewise a good strategy will contribute to the organizational growth that can appear in various forms such as market development. Thus, based on the experts' opinions if the first to the fourth ranked factors are taken as the key external success factors of OI, the strategy with the fifth rank is the connecting ring of the created tour by ACO, which defines internal orientation of the organization based on the first four factors. In addition, Universities and research institutions hold the 11th and 12th rank respectively. This originates from lack of coordination between these centers and industrial enterprises. Since researches output is not suitable for industry in Iran and normally have conducted without feasibility study. Therefore, companies do not tend to consider their findings and they connect to them only in necessary cases after formulating their strategies.

\section{CONCLUSiOn}

The paper aims to identify the best ranking of the most important effective factors in OI success in MSMEs in Iran. In the first stage, the most important factors identified using structural equation modelling. Next, each factor's impact on the others investigated applying Fuzzy DEMATEL. In the end, based on asymmetric TSP, the best-formed tour determined using ACO Algorithm, which demonstrates the highest accumulative impact or the best ranking of OI success factors in MSMEs. Generally, OI studies are categorized into two groups. The first one includes systematic reviews of OI such as Bogers et al. [5], Ibarra et al. [33], Stucki [48], and Smith et al. [46]. The second group includes the studies investigating OI dimensions, influential factors, and the impact of managerial concepts on OI like Bogers et al. [6], Brunswicker and Chesbrough [8], Vanhaverbeke et al. [49], and Brunswicker and Ehrenmann [9]. OI in SMEs has attracted researchers' attention in recent years, for instance Freel and Robson [26], Pervan et al. [40], and Lee et al. [36]; however, manufacturing SMEs have been scarcely studied especially and comprehensively. In terms of theoretical implications, the paper is virtually the first case of combination fuzzy decision support tools (DEMATEL) with artificial intelligence (asymmetric Ant Colony Optimization) and it shows using ACO can optimized the ranking of open innovation among MSMEs.

The primary results of the first stage show that competitors, partners, universities, research institutions, suppliers, economic factors and ecological issues have been chosen as the most important external OI factors in MSMEs. After calculating the impact of identified factors on other factors in the second stage based on 12 experts' opinions, the best ranking of OI success factors in MSMEs determined by ACO metaheuristic algorithm. The findings based on importance demonstrate that economic factors, suppliers, competitors, partners, firm's strategy, firm's structure, reward system, employees, IT support, organizational learning, universities, research institutions, and ecological issues hold the first to the thirteenth rank.

As managerial implications, according to the results, the following recommendations are offered to the MSMEs:

- Developing the relationships with universities and research institutions can be very useful and effective since they can be the origin of innovations. Thus, in order to create accordance between industrial sectors' needs and university outputs, enterprises must announce their research areas needed to them annually. This action is more important for those companies, which suffer from limited sources or using outside-in OI process.

- Since partners is a key extra-organizational factor, co-working production enterprises must try to formulate their innovative strategies in accordance with each other to benefit from more strength towards their rivals.

- MSMEs tending to apply OI strategy, in order to decrease their R\&D costs and risks, must have exact plans for organizational learning, rewarding system, employees and suppliers because innovation cycles may lead to change in company's suppliers. Based on the findings, the suppliers hold the second rank among OI success factor. Thus, MSMEs must always have a list of suppliers in their working ground. 
- Employees are the innovation core in enterprises applying inside-out OI process and thus an appropriate rewarding system is of great significance in retaining and encouraging them to improve innovative activities. Also taking actions to create grounds for organizational learning to improve employees' knowledge in enterprises with outside-in OI process is vital.

- Attention to ecological issues and MSMEs' focus on these concerns, pave the way of innovation, current market development and creating new markets.

In terms on research limitations, three main restrictions including: (1) Lack of integrated software to perform calculations of fuzzy DEMATEL technique increases the time of calculations and the probability of errors in calculations. (2) The impossibility of checking the accuracy of the answers is another limitation in studies which data is formed according to the respondents' opinions. (3) Using the concept of OI in MSMEs in developing countries such as Iran is considered as a new approach and this makes it not only difficult to find competent people to answer research questions, but also different dimensions are still needed for study. Based on mentioned limitations, new concept of OI in MSMEs in Iran, and interviews with experts, recommendations for future studies can be proposed as follow: (1) Studying the best ranking of influential factors in OI success with other algorithms such as genetic algorithm to compare the results. (2) Designing a Fuzzy expert system for a feasibility study of performing OI processes in organization. (3) Offering a numerical coefficient based on the identified factors in order to evaluate the openness of $R \& D$ processes.

\section{Appendix A.}

\section{Stage 1 Questionnaire: Factor analysis}

\section{Dear responder}

To identify the most important intra and extra organizational open innovation (OI) success factors, we are proud to use your valuable comments. Your answer leads to more validity of this research. It is worth mentioning that all information received will be used only for statistical analysis and will not be published or used for any other purpose.

It you have any question, please let us know.

Thanks a lot

\begin{tabular}{ll}
\hline \multicolumn{2}{c}{ Demographic information } \\
\hline Gender: $\quad \mathrm{F}: \mathrm{M}:$ \\
Education: & \\
Work experience (year): & \\
\hline
\end{tabular}

\section{Further information}

Open Innovation: in the OI model, the boundaries between the company and the environment are permeable, which makes it easy to enter and exit knowledge through different channels at different phases of the innovation process. Implementing OI depends not only on external factors but also on internal factors of the organization and managers must be able to control the organization in both contexts.

Please score to each factor using Likert scale. 


\begin{tabular}{|c|c|c|c|c|c|c|c|c|c|c|c|c|c|}
\hline \multicolumn{14}{|c|}{ Questionnaire } \\
\hline & $\begin{array}{c}\text { Intra-organizational } \\
\text { factors }\end{array}$ & 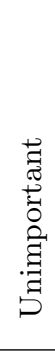 & 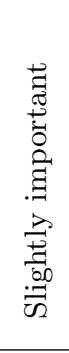 & 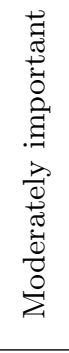 & 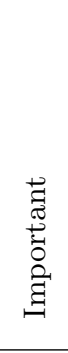 & 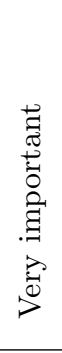 & & $\begin{array}{c}\text { Extra-organizational } \\
\text { Factors }\end{array}$ & 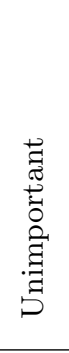 & 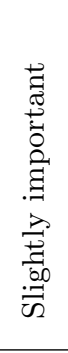 & 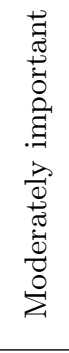 & 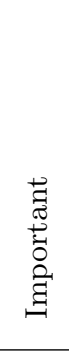 & 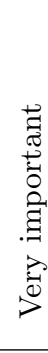 \\
\hline $\mathrm{I}_{1}$ & Firm's strategy & & & & & & $E_{1}$ & Competitors & & & & & \\
\hline $\mathrm{I}_{2}$ & Firm's structure & & & & & & $\mathrm{E}_{2}$ & Partners & & & & & \\
\hline $\mathrm{I}_{3}$ & Leadership style & & & & & & $\mathrm{E}_{3}$ & Universities & & & & & \\
\hline $\mathrm{I}_{4}$ & OI process & & & & & & $\mathrm{E}_{4}$ & Research institutions & & & & & \\
\hline $\mathrm{I}_{5}$ & Financial resources & & & & & & $\mathrm{E}_{5}$ & Customers & & & & & \\
\hline $\mathrm{I}_{6}$ & Firm's technology & & & & & & $\mathrm{E}_{6}$ & Suppliers & & & & & \\
\hline $\mathrm{I}_{7}$ & Knowledge management & & & & & & $\mathrm{E}_{7}$ & Government support & & & & & \\
\hline $\mathrm{I}_{8}$ & IT support & & & & & & $\mathrm{E}_{8}$ & Economic factors & & & & & \\
\hline $\mathrm{I}_{9}$ & External relationships & & & & & & $\mathrm{E}_{9}$ & Political/Legal factors & & & & & \\
\hline $\mathrm{I}_{10}$ & Outsourcing R\&D & & & & & & $\mathrm{E}_{10}$ & Ecological issues & & & & & \\
\hline $\mathrm{I}_{11}$ & Absorptive capacity & & & & & & $\mathrm{E}_{11}$ & External search breadth & & & & & \\
\hline $\mathrm{I}_{12}$ & Organisational capabilities & & & & & & $\mathrm{E}_{12}$ & External search depth & & & & & \\
\hline $\mathrm{I}_{13}$ & Organizational learning & & & & & & $\mathrm{E}_{13}$ & Technology & & & & & \\
\hline $\mathrm{I}_{14}$ & Organizational culture & & & & & & $\mathrm{E}_{14}$ & Firm size & & & & & \\
\hline $\mathrm{I}_{15}$ & Employees & & & & & & & & & & & & \\
\hline $\mathrm{I}_{16}$ & Team work & & & & & & & & & & & & \\
\hline $\mathrm{I}_{17}$ & Reward system & & & & & & & & & & & & \\
\hline
\end{tabular}

\section{Stage 2 Questionnaire: Fuzzy DEMATEL}

\section{Dear responder}

To investigate causal relations among the most important open innovation (OI) success factors, we are proud to use your valuable comments. Your answer leads to more validity of this research. It is worth mentioning that all information received will be used only for statistical analysis and will not be published or used for any other purpose.

It you have any question, please let us know.

Thanks a lot

\begin{tabular}{ll}
\hline \multicolumn{2}{c}{ Demographic information } \\
\hline Gender: & F: $\mathrm{M}:$ \\
Education: & \\
Work experience (year): & \\
\hline
\end{tabular}

\section{Further information}

- Open Innovation: in the OI model, the boundaries between the company and the environment are permeable, which makes it easy to enter and exit knowledge through different channels at different phases of the innovation process. Implementing OI depends not only on external factors but also on internal factors of the organization and managers must be able to control the organization in both contexts.

- How to response the questionnaire: in this questionnaire, you must specify the effect of each factor in each row on factors in each column, which is important according to the scoreboard below. 


\begin{tabular}{lllll}
\hline No effect & Low effect & Medium effect & High effect & Very high effect \\
\hline 0 & 1 & 2 & 3 & 4 \\
\hline
\end{tabular}

Please attention, for example, if the effect of factor $A$ on factor $B$ is high, the effect of factor $B$ on factor $A$ can be higher, equal, lower, or zero. In fact, both factors can affect each other or have no effect at all.

\begin{tabular}{|c|c|c|c|c|c|c|c|c|c|c|c|c|c|}
\hline Fuzzy DEMATEL technique & 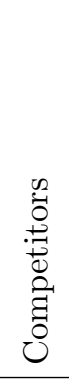 & 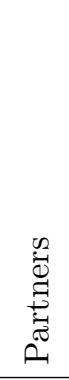 & 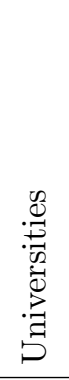 & 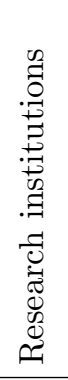 & 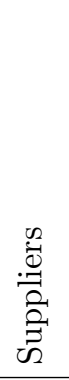 & 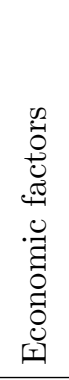 & 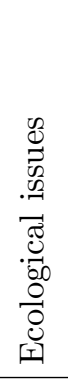 & 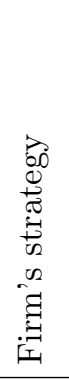 & 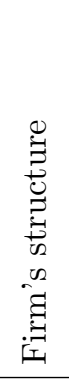 & 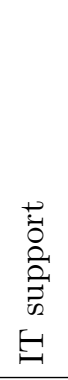 & 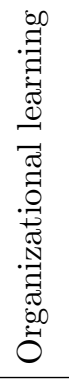 & 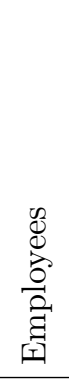 & 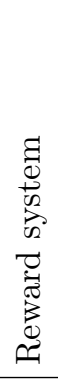 \\
\hline Competitors & 0 & & & & & & & & & & & & \\
\hline Partners & & 0 & & & & & & & & & & & \\
\hline Universities & & & 0 & & & & & & & & & & \\
\hline Research institutions & & & & 0 & & & & & & & & & \\
\hline Suppliers & & & & & 0 & & & & & & & & \\
\hline Economic factors & & & & & & 0 & & & & & & & \\
\hline Ecological issues & & & & & & & 0 & & & & & & \\
\hline Firm's strategy & & & & & & & & 0 & & & & & \\
\hline Firm's structure & & & & & & & & & 0 & & & & \\
\hline IT support & & & & & & & & & & 0 & & & \\
\hline Organizational learning & & & & & & & & & & & 0 & & \\
\hline Employees & & & & & & & & & & & & 0 & \\
\hline Reward system & & & & & & & & & & & & & 0 \\
\hline
\end{tabular}

\section{REFERENCES}

[1] F. Altuntas and M.Ş. Gök, Technological evolution of wind energy with social network analysis. Kybernetes 50 (2021) 11801211.

[2] F. Altuntas and M.Ş. Gök, Analysis of patent documents with utility mining: a case study of wind energy technology. Kybernetes 50 (2020) 2548-2582.

[3] N.A.H. Abdullah, A.H. Ahmad, N. Zainudin and R.M. Rus, Modelling small SMEs' failure in Malaysia. Int. J. Entrepreneurship Small Bus. 28 (2016) 101-116.

[4] A. Bajracharya, Public transportation and private car: a system dynamics approach in understanding the mode choice. IJSDA 5 (2016) 1-18.

[5] M. Bogers, H. Chesbrough and C. Moedas, Open innovation: research, practices, and policies. California Manage. Rev. 60 (2018) 5-16.

[6] M. Bogers, N.J. Foss and J. Lyngsie, The human side of open innovation: the role of employee diversity in firm-level openness. Res. Policy 47 (2018) 218-231.

[7] S. Bouamama, C. Blum and J.G. Fages, An algorithm based on ant colony optimization for the minimum connected dominating set problem. Appl. Soft Comput. 80 (2019) 672-686.

[8] S. Brunswicker and H. Chesbrough, The adoption of open innovation in large firms: practices, measures, and risks a survey of large firms examines how firms approach open innovation strategically and manage knowledge flows at the project level. Res.-Technol. Manage. 61 (2018) 35-45.

[9] S. Brunswicker and F. Ehrenmann, Managing open innovation in SMEs: a good practice example of a German software firm. IJIEM 4 (2013) 33-41.

[10] B. Chang, C.W. Chang and S.H. Wu, Fuzzy DEMATEL method for developing supplier selection criteria. Expert Syst. Appl. 38 (2011) 1850-1858.

[11] J.K. Chen and I.S. Chen, Using a novel conjunctive MCDM approach based on DEMATEL, fuzzy ANP, and TOPSIS as an innovation support system for Taiwanese higher education. Expert Syst. App. 37 (2010) 1981-1990.

[12] J. Chen, Y. Chen and W. Vanhaverbeke, The influence of scope, depth, and orientation of external technology sources on the innovative performance of Chinese firms. Technovation 31 (2011) 362-373. 
[13] Z. Chen, M. Lu, X. Ming, X. Zhang and T. Zhou, Explore and evaluate innovative value propositions for smart product service system: a novel graphics-based rough-fuzzy DEMATEL method. J. Cleaner Prod. 243 (2020) 118672.

[14] H.W. Chesbrough, Open Innovation: The New Imperative for Creating and Profiting From Technology. Harvard Business Press (2003).

[15] H. Chesbrough, The era of open innovation. Manage. Rev. 44 (2003) 35-41.

[16] H. Chesbrough, The future of open innovation: the future of open innovation is more extensive, more collaborative, and more engaged with a wider variety of participants. Res.-Technol. Manage. 60 (2017) 35-38.

[17] H. Chesbrough and A.K. Crowther, Beyond high tech: early adopters of open innovation in other industries. REBD Manage. 36 (2006) 229-236.

[18] L. Dahlander and D.M. Gann, How open is innovation. Res. policy 39 (2010) 699-709.

[19] J. Dufour and P.E. Son, Open innovation in SMEs - towards formalization of openness. J. Innov. Manage. 3 (2015) 90-117.

[20] O. Engin and A. Güçlü, A new hybrid ant colony optimization algorithm for solving the no-wait flow shop scheduling problems. Appl. Soft Comput. $\mathbf{7 2}$ (2018) 166-176.

[21] E. Enkel and O. Gassmann, Driving open innovation in the front end: the IBM case. In: EURAM Conference, Paris, France (2007).

[22] E. Enkel, O. Gassmann and H. Chesbrough, Open R\&D and open innovation: exploring the phenomenon. RED Manage. 39 (2009) 311-316.

[23] D. Faems, M. De Visser, P. Andries and B. Van Looy, Technology alliance portfolios and financial performance: value-enhancing and cost-increasing effects of open innovation. J. Prod. Innov. Manage. 27 (2010) 785-796.

[24] C. Feng and R. Ma, Identification of the factors that influence service innovation in manufacturing enterprises by using the fuzzy DEMATEL method. J. Cleaner Prod. 253 (2020) 120002.

[25] H. Forsman and S. Temel, Innovation and business performance in small enterprises: an enterprise-level analysis. Int. J. Innov. Manage. 15 (2011) 641-665.

[26] M. Freel and P.J. Robson, Appropriation strategies and open innovation in SMEs. Int. Small Bus. J. 35 (2017) 578-596.

[27] C. García-Martínez, O. Cordón and F. Herrera, A taxonomy and an empirical analysis of multiple objective ant colony optimization algorithms for the bi-criteria TSP. Eur. J. Oper. Res. 180 (2007) 116-148.

[28] M. Gershman, V. Roud and T.W. Thurner, Open innovation in Russian state-owned enterprises. Ind. Innov. 26 (2019) $199-217$.

[29] M. Greco, M. Grimaldi and L. Cricelli, Benefits and costs of open innovation: the BeCO framework. Technol. Anal. Strategic Manage. 31 (2019) 53-66.

[30] J. Han and A. Heshmati, Determinants of financial rewards from industry-university collaboration in South Korea. Int. J. Innov. Manage. 20 (2016) 1650075.

[31] M. Heikkilä, H. Bouwman and J. Heikkilä, From strategic goals to business model innovation paths: an exploratory study. J. Small Bus. Enterp. Dev. 25 (2018) 107-128.

[32] Q. Hu, S. Williams, R. Mason and P. Found, Knowledge management in consultancy-involved process improvement projects: cases from Chinese SMEs. Prod. Planning Control 30 (2019) 866-880.

[33] E. Ibarra, J. Rueda and A. Arenas, Mapping of the challenges for the open innovation model's implementation in service sector. J. Adv. Manage. Sci. 3 (2015) 354-361.

[34] B. Kanso, A. Kansou and A. Yassine, Open capacitated ARC routing problem by hybridized ant colony algorithm. RAIRO: OR 55 (2021) 639-652.

[35] M.M. Keupp and O. Gassmann, Determinants and archetype users of open innovation. RED Manage. 39 (2009) 331-341.

[36] S. Lee, G. Park, B. Yoon and J. Park, Open innovation in SMEs-An intermediated network model. Res. Policy 39 (2010) 290-300.

[37] Y. Mehrjerdi and A. Nadizadeh, Using greedy clustering method to solve capacitated location routing problem with fuzzy demands. Eur. J. Oper. Res. 229 (2013) 75-84.

[38] L. Mortara and T. Minshall, How do large multinational companies implement open innovation? Technovation 31 (2011) 586-597.

[39] A. Nadizadeh and H.H. Nasab, Solving the dynamic capacitated location-routing problem with fuzzy demands by hybrid heuristic algorithm. Eur. J. Oper. Res. 238 (2014) 458-470.

[40] S. Pervan, Y. Al-Ansaari and J. Xu, Environmental determinants of open innovation in Dubai SMEs. Ind. Market. Manage. 50 (2015) 60-68.

[41] D. Radicic and K. Djalilov, The impact of technological and non-technological innovations on export intensity in SMEs. J. Small Bus. Enterp. Dev. 26 (2019) 612-638.

[42] G. Santoro, D. Vrontis, A. Thrassou and L. Dezi, The internet of things: building a knowledge management system for open innovation and knowledge management capacity. Technol. Forecasting Soc. Change 136 (2018) 347-354.

[43] M. Shafiei Nikabadi and A. Hakaki, A dynamic model of effective factors on open innovation in manufacturing small and medium sized companies. IJSDA 7 (2018) 1-26.

[44] M. Shafiei Nikabadi and A. Hakaki, A multi-dimensional causal model of effective factors on open innovation in manufacturing SMEs in Iran. IJABIM 10 (2019) 91-110.

[45] M. Shafiei Nikabadi and A. Hakaki, Mutual relationship between supply chain, business strategy, and knowledge management in supply chain. In: Dynamic Perspectives on Globalization and Sustainable Business in Asia. IGI Global Press (2019).

[46] M. Smith, M. Busi, P. Ball and R. Van der Meer, Factors influencing an organisation's ability to manage innovation: a structured literature review and conceptual model. Int. J. Innov. Manage. 12 (2008) 655-676. 
[47] A. Spithoven, W. Vanhaverbeke and N. Roijakkers, Open innovation practices in SMEs and large enterprises. Small Bus. Econ. 41 (2013) 537-562.

[48] A. Stucki, Internal and external factors influencing the implementation and diffusion of the open innovation models: the case of the postal sector. In: Proceedings of the 3rd Global Postal Research and Education Network Conference. Lausanne, Switzerland (2009).

[49] W. Vanhaverbeke, N. Roijakkers, A. Lorenz and H. Chesbrough, The Importance of Connecting Open Innovation to Strategy. Springer Press (2017).

[50] W.W. Wu and Y.T. Lee, Developing global managers' competencies using the fuzzy DEMATEL method. Expert Syst. App. 32 (2007) 499-507.

\section{Subscribe to Open (S20) A fair and sustainable open access model}

This journal is currently published in open access under a Subscribe-to-Open model (S2O). S2O is a transformative model that aims to move subscription journals to open access. Open access is the free, immediate, online availability of research articles combined with the rights to use these articles fully in the digital environment. We are thankful to our subscribers and sponsors for making it possible to publish this journal in open access, free of charge for authors.

\section{Please help to maintain this journal in open access!}

Check that your library subscribes to the journal, or make a personal donation to the $\mathrm{S} 2 \mathrm{O}$ programme, by contacting subscribers@edpsciences.org

More information, including a list of sponsors and a financial transparency report, available at: https://www. edpsciences.org/en/maths-s2o-programme 